\title{
Statin-mediated reduction of osteopontin expression induces apoptosis and cell growth arrest in ovarian clear cell carcinoma
}

\author{
MOTOKI MATSUURA, TAKAHIRO SUZUKI, MIWA SUZUKI, \\ RYOICHI TANAKA, EIKI ITO and TSUYOSHI SAITO \\ Department of Obstetrics and Gynecology, Sapporo Medical University, Sapporo, Japan
}

Received August 12, 2010; Accepted October 1, 2010

DOI: 10.3892/or_00001039

\begin{abstract}
Poor prognosis in ovarian clear cell carcinoma is associated with the expression of a defined set of proteins including osteopontin (OPN) and integrin. Statins, a family of 3-hydroxy-3-methylglutaryl CoA reductase inhibitors, are currently being investigated for the treatment and prevention of cancer. In this study, we investigated the effects of simvastatin on ovarian clear cell carcinoma (OCCC) cells in vitro and in vivo and elucidated the mechanism of drug action. Changes in OPN gene expression were determined by real-time RT-PCR, and an MTT assay was performed to determine effects on cell proliferation. Finally, a xenograft tumor model was constructed to evaluate the effects of simvastatin on cell proliferation and apoptosis in vivo. According to our experimental results, OPN is an important protein in OCCC. Simvastatin inhibited OCCC cell proliferation, and the inhibition rate was approximately $40 \%$ to $50 \%$ after treatment with $10 \mu \mathrm{M}$ simvastatin for $48 \mathrm{~h}$. In the xenograft studies, simvastatin treatment resulted in a significant growth inhibition. Furthermore, the mice treated with simvastatin survived significantly longer compared to the control groups. In conclusion, simvastatin has anticancer effects in vitro and in vivo. Further confirmation of the anticancer effects of statins in future studies will increase the scope for OCCC treatment.
\end{abstract}

\section{Introduction}

Osteopontin (OPN), a secreted calcium-binding glycophosphoprotein, originally was viewed as a mediator of bone remodeling and tissue debridement (1). However, previously it has been implicated in numerous physiological and pathological events including immunity, inflammation, tumor progression and cell survival $(2,3)$. Recent studies have

Correspondence to: Dr Motoki Matsuura, Department of Obstetrics and Gynecology, Sapporo Medical University, Sapporo 060-8543, Japan

E-mail: mmatsuura@sapmed.ac.jp

Key words: ovarian clear cell carcinoma, osteopontin, statin revealed that OPN expression correlates with the progression and metastasis of various cancers (4-6), and clinical studies have clearly shown that OPN expression is increased in ovarian cancer (7-9). In addition, OPN expression is significantly higher in the plasma of patients with epithelial ovarian cancer (9). Microarray analysis of gene expression identified genes that are highly overexpressed in ovarian cancers (10). Of these genes, OPN was highly elevated in OCCC (11). OPN immunolocalization confirmed that OCCC expression is increased in comparison to healthy ovarian epithelium (8).

We previously reported that OPN expression is increased in OCCC, and down-regulation of OPN by treatment with simvastatin, or transfection with OPN-specific siRNA in vitro, reduced cell invasiveness (12).

Statins are 3-hydroxy-3-methylglutaryl coenzyme A (HMG-CoA) reductase inhibitors that prevent the conversion of HMG-CoA to mevalonate and reduce cholesterol synthesis. Statins are typically used to lower low-density lipoprotein (LDL) cholesterol for the treatment of hypercholesterolemia (13). In addition to reducing cholesterol synthesis, statins inhibit the synthesis of the cholesterol isoprenoid intermediates farnesylpyrophosphate (FPP) and geranylgeranyl pyrophosphate (GGPP) (14). These isoprenoids attach to several cellular proteins such as oncoproteins (ras), nuclear proteins (laminins) and small guanosine triphosphate (GTP)-binding proteins (rho, rac, rab). Isoprenylation or post-translational modification is essential to signal transduction that promotes cell proliferation, differentiation and cell death (15). Various studies have described the association of statins with a decrease in the incidence of various cancers $(16,17)$.

In a previous study, statin use lowered plasma OPN concentrations (18). Other research has demonstrated that statins reduced both protein and mRNA OPN expression (19). In the present study, we evaluated the in vitro and in vivo effects of statin (simvastatin) treatment on cell proliferation and apoptosis in OCCC cells (RMG-1 and TOV-21G).

\section{Materials and methods}

Materials. Simvastatin was obtained from Sigma-Aldrich (St. Louis, USA) and dissolved in DMSO (Sigma-Aldrich).

Cell lines and cultures. The following ovarian cancer cell lines were used for the in vitro and in vivo studies: clear cell 
carcinoma, RMG-1 (JCRB Cell Bank, Osaka, Japan) and TOV-21G (ATCC, VA, USA). Cells were cultured in RPMI1640 (Invitrogen, CA, USA) containing $10 \%$ fetal bovine serum (Invitrogen) in a humidified atmosphere of $5 \% \mathrm{CO}_{2}$ and $95 \%$ air at $37^{\circ} \mathrm{C}$.

Quantitative real-time RT-PCR analysis. Total RNA was isolated from cell cultures using commercial spin columns (RNeasy; Qiagen, Tokyo, Japan) in accordance with the manufacturer's instructions. cDNA synthesis was performed using the ThermoScript ${ }^{\mathrm{TM}}$ RT-PCR system (Invitrogen). Real-time quantitative RT-PCR (20) was used to measure OPN mRNA expression in the cell lines. Reactions $(50 \mu \mathrm{l})$ contained the following reagents: $0.5 \mu 1 \mathrm{cDNA}, 25 \mu 12 \mathrm{X}$ iQ SYBR Green Supermix (Bio-Rad, CA, USA), $23.5 \mu 1$ sterile water, and $0.5 \mu \mathrm{l}(0.1 \mu \mathrm{M})$ OPN forward and reverse primers from a $10-\mu 1$ solution (Sigma-Aldrich). The housekeeping gene glyceraldehyde-3-phosphatedehydregenase (GAPDH) was also measured. Amplification of OPN cDNA was performed using the following cycling profile: initial denaturation at $95^{\circ} \mathrm{C}$ for $10 \mathrm{~min}$ and 40 cycles of $15 \mathrm{sec}$ at $95^{\circ} \mathrm{C}$, and $1 \mathrm{~min}$ at $60^{\circ} \mathrm{C}$ in a Chromo $4^{\mathrm{TM}}$ system (Bio-Rad). To determine the relative expression of OPN in each sample, the comparative $\mathrm{C}_{\mathrm{T}}$ method was used as described previously (20). The GAPDH $C_{T}$ value was subtracted from the OPN $C_{T}$ value for each sample to calculate a $\Delta \mathrm{C}_{\mathrm{T}}$ value. The difference $\left(\Delta \Delta C_{T}\right)$ between the $\Delta C_{T}$ value of each sample and the highest $\Delta \mathrm{C}_{\mathrm{T}}$ value (calibration value) was then calculated. The relative level of OPN gene expression was expressed as $2^{-\Delta \Delta C_{\mathrm{r}}}$.

MTT assay. The MTT assay was performed to evaluate the effects of simvastatin on cell survival. RMG-1 and TOV-21G cells $\left(5 \times 10^{4}\right.$ cells $)$ were seeded in 24 -well plates and incubated overnight. The following day, simvastatin (0-10 $\mu \mathrm{M})$ was added to each plate, and the plates were cultured for an additional $48 \mathrm{~h}$. After this incubation, $100 \mu \mathrm{l}$ of an MTT stock solution: $5 \mathrm{mg}$ MTT/1 ml phosphate-buffered saline (PBS), was added to each well, and the plates were incubated for $4 \mathrm{~h}$ at $37^{\circ} \mathrm{C}$. Finally, the media were replaced with $100 \mu 1$ of DMSO. One hundred microliters was then transferred to 96well plates. Absorbance was read at $550 \mathrm{~nm}$ on a microplate reader (Bio-Rad), and the control wells were set to $100 \%$ cell viability. Three individual experiments were performed in triplicate.

Treatment of mice with simvastatin. RMG-1 and TOV-21G cells $\left(5 \times 10^{6}\right.$ cells $)$ in $0.1 \mathrm{ml}$ of culture medium were injected subcutaneously in the left flank region of 6-week-old female NOD/SCID mice (Hokudo, Sapporo, Japan). The mice were randomly assigned to two groups: group 1, saline treatment $(\mathrm{n}=3)$; group $2,15 \mathrm{mg} / \mathrm{kg} /$ day simvastatin treatment $(\mathrm{n}=3)$. Saline and simvastatin were injected intraperitoneally every day for 10 days starting 1 day post-implantation. Tumor volumes were measured every 5 days and calculated as a rotational ellipsoid ( $\mathrm{a} \times \mathrm{b}^{2} \times 0.5$; ' $\mathrm{a}$ ' is the long axis, and ' $\mathrm{b}$ ' is the transverse axis). Survival time was used as the primary endpoint.

A separate in vivo study was performed to measure OPN mRNA and protein expression. The mice were randomly

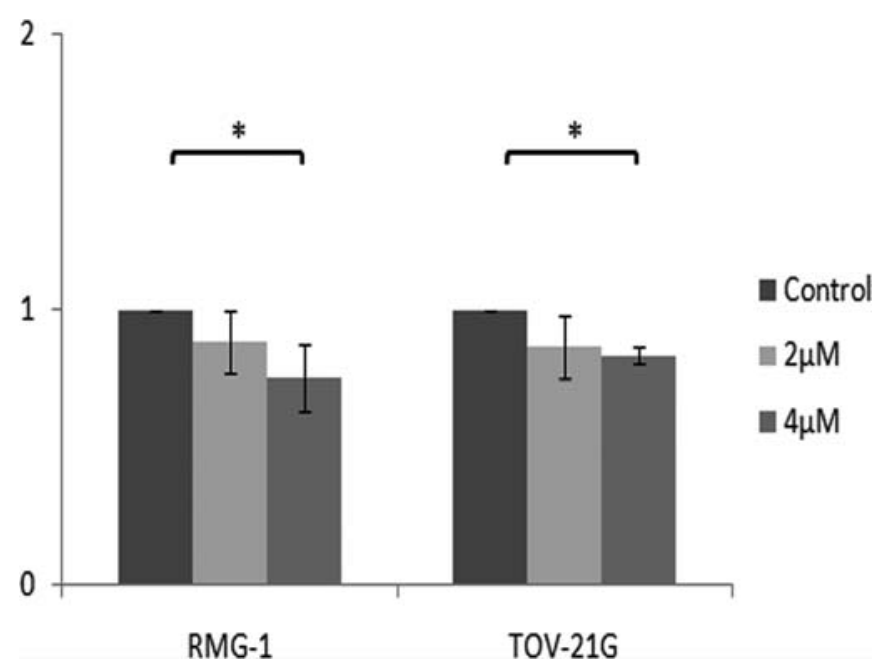

Figure 1. Simvastatin influences the levels of OPN. Two OCCC cell lines were treated with $0-4 \mu \mathrm{M}$ simvastatin for $48 \mathrm{~h}$. The levels of OPN mRNA expression were significantly decreased in this analysis $\left({ }^{*} \mathrm{P}<0.05\right)$.

assigned to two groups (see above), and after tumors became visible, the mice were injected intraperitoneally every day for 10 days. Mice were then sacrificed, and the tumors were excised $24 \mathrm{~h}$ after the final simvastatin treatment. RNA was isolated from tissues using TRIZOL Reagent (Invitrogen) following the manufacturer's instructions. In addition, resected tumors were fixed with $10 \%$ buffered formalin and $70 \%$ ethanol. OPN protein expression was then determined by immunofluorescent staining as follows. Fixed tumor tissue was incubated with a mouse anti-human monoclonal antibody (clone 1B20, IBL, Gunma, Japan) (21) followed by an incubation with secondary antibodies tagged with Alexa Fluor $^{\circledR} 488$ and goat anti-mouse IgG (Molecular Probes, OR, USA). Immunofluorescence was visualized as described previously (22) with some modifications. Briefly, chamber slides were rinsed in PBS and incubated overnight at $4^{\circ} \mathrm{C}$ with the primary antibody. After 3 rinses in PBS for $10 \mathrm{~min}$ each, the slides were incubated with secondary antibodies for $30 \mathrm{sec}$ at room temperature followed by 3 washes with PBS for $15 \mathrm{~min}$ each. The sections were then mounted using Fluorescent Mounting Medium (Dako Cytomation, CA, USA), overlaid with a coverslip, and examined under a fluorescent microscope (Olympus, Japan). All animal experiments were approved by the institutional animal care and use committee.

TUNEL assay for detection of apoptotic cells in vivo. To examine apoptosis in resected tumors, DNA fragmentation was measured using the TUNEL assay. This was performed using the ApopTag Fluorescein In Situ Apoptosis Detection kit (Chemicon, MA, USA) according to the manufacturer's instructions.

Statistical analysis. Statistical analysis was performed using Statview ${ }^{\circledR} 5.0$ (Hulinks, Tokyo, Japan) software. The statistical differences between 2 groups were analyzed using the MannWhitney U-test (nonparametric data), and differences among multiple groups were analyzed using the Kruskal-Wallis test. 


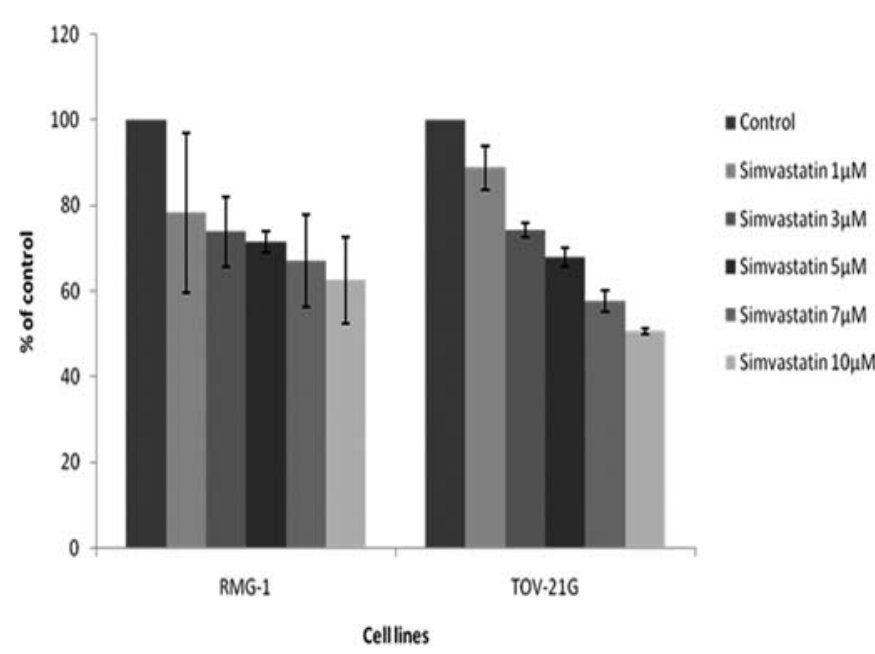

Figure 2. Inhibition of OCCC proliferation after exposure to simvastatin. Cells were treated with simvastatin $(1-10 \mu \mathrm{M})$ for $48 \mathrm{~h}$, and the MTT assay demonstrated dose-dependently reduced cell proliferation.

$\mathrm{P}<0.05$ were considered significant. Survival rates were analyzed using the Kaplan-Meier method (23). The log-rank test was used to determine the difference between two groups.

\section{Results}

Simvastatin reduces OPN $m R N A$ expression in vitro. To determine the influence of simvastatin on OPN expression in vitro, two OCCC cell lines were treated with 0-4 $\mu \mathrm{M}$ simvastatin for $48 \mathrm{~h}$ in 6-well plates (Fig. 1). Total RNA was isolated, and OPN mRNA expression was analyzed by realtime RT-PCR. The expression level in the $0 \mu \mathrm{M}$ group was assigned a value of 1 . Data are shown as the mean \pm SD. OPN mRNA expression significantly decreased in two cell lines in $4 \mu \mathrm{M}$ (RMG-1: 1.33 times, and TOV-21G: 1.20 times; $\mathrm{P}<0.05)$. This experiment was repeated 3 times with triplicate samples.

Simvastatin causes a dose-dependent decrease in ovarian clear cell carcinoma cell proliferation. To evaluate the effect of simvastatin on OCCC cell growth, two cell lines were treated with various concentrations of simvastatin for $48 \mathrm{~h}$ in 24-well plates. As depicted in Fig. 2, simvastatin reduced cell proliferation dose-dependently, and survival was significantly reduced to $62.5 \%$ (RMG-1) and $50.7 \%$ (TOV-21G) with $10 \mu \mathrm{M}$ simvastatin $(\mathrm{P}<0.05)$. Experiments were repeated 3 times with triplicate samples.

Simvastatin reduces OPN mRNA expression in the tissues of NOD/SCID mice. To determine the effects of simvastatin on OPN expression in vivo, OCCC cell proliferation was measured in mice. Tumors became visible about 15 days after implantation of the two cell lines. Simvastatin was injected intraperitoneally every day for 10 days into mice. Total RNA was then isolated from freshly isolated tissue samples, and OPN mRNA expression of the subcutaneous tumor was determined by real-time RT-PCR (Fig. 3). The mRNA expression in the treatment group was assigned a value of 1 .

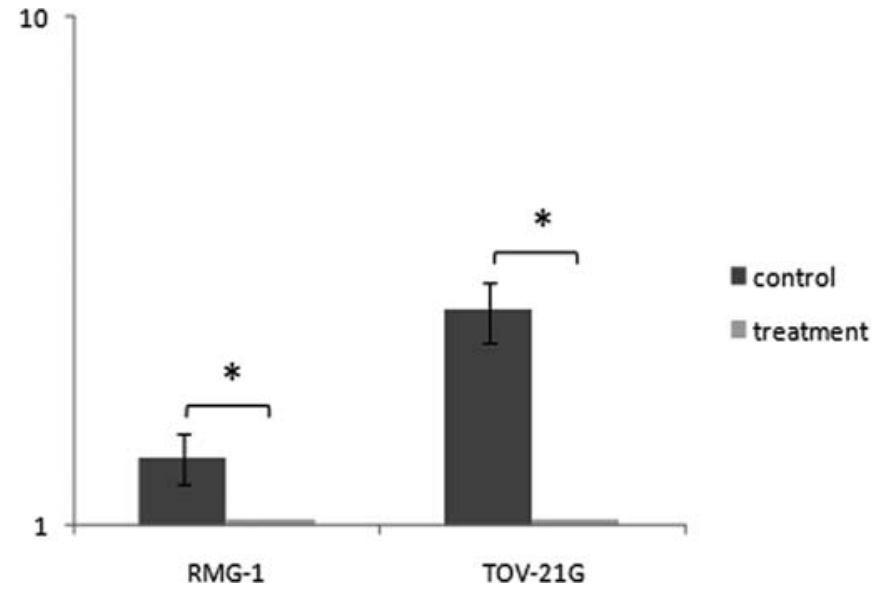

Figure 3. Simvastatin reduced OPN expression in the in vivo models. OPN expression was determined by real-time RT-PCR. The levels of OPN mRNA expression were significantly decreased in the simvastatin-treated groups $\left({ }^{*} \mathrm{P}<0.05\right)$.

Values are shown as the mean $\pm \mathrm{SD}$. Similar to the in vitro study results, OPN mRNA expression was significantly decreased in the treatment groups (RMG-1: 1.36 times, and TOV-21G: 2.65 times; $\mathrm{P}<0.05$ ).

Simvastatin decreases OPN protein expression in model mice. To determine the effects of simvastatin treatment on OPN protein expression in vivo, immunofluorescent staining was performed to the subcutaneous tumor of the mice. As shown in Fig. 4, OPN staining was observed at the cell membrane and in the cytoplasm, and OPN staining was highly increased in the control group (Fig. 4A) in comparison to the treatment group (Fig. 4B). These data suggest that simvastatin treatment reduces OPN protein expression. Fig. 4 is presented for the tumors generated by RMG-1 cells.

Simvastatin-induced apoptosis. The TUNEL assay detects early-stage apoptosis in systems with chromatin condensation and few strand breaks. Propidium iodide (PI) was used with fluorescein (FITC). DNA in the nucleus was stained with PI (red) and FITC (green) and visualized by fluorescence microscopy. Fig. 5 is presented for the tumors generated by RMG-1 cells. Apoptosis was increased in simvastatin-treated mice (Fig. 5B) in comparison to control mice (Fig. 5A).

Antitumor effects of simvastatin in ovarian clear cell adenocarcinoma in immunodeficient mice. We determined the effects of simvastatin on tumor growth and mouse survival (Fig. 6). In the control group, tumors became visible 15 days after implantation of the two cell lines. In comparison, tumors became visible 25 days after implantation in the simvastatintreated group. We observed significant growth inhibition compared with the control group when both cell lines were tested $(\mathrm{P}<0.05)$. Furthermore, we examined the effect of simvastatin treatment on the survival of immunodeficient mice. Whereas every mouse died within 80 days (RMG-1) and 65 days (TOV-21G), the mice treated with simvastatin survived significantly longer $(\mathrm{P}<0.05)$. The 90 -day survival rate was $66.7 \%$ using the two cell lines. In this study, $15-\mathrm{mg} / \mathrm{kg} /$ day 

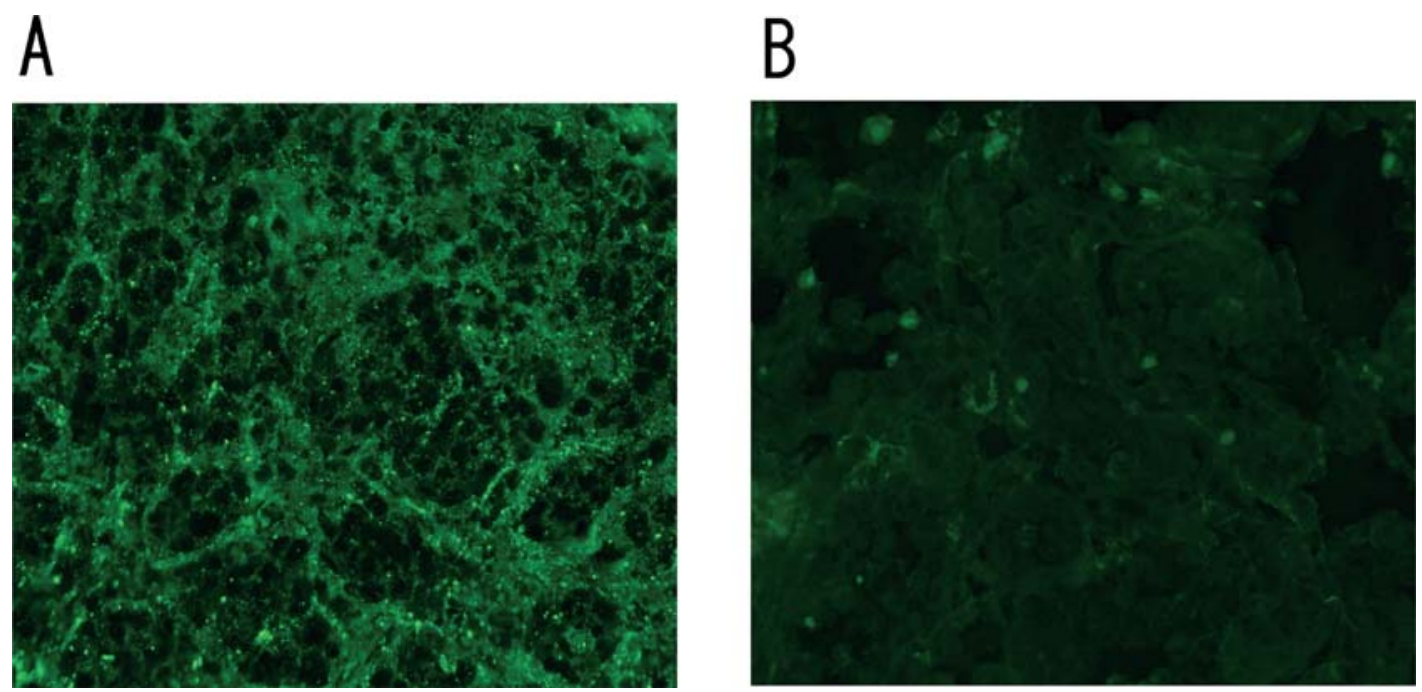

Figure 4. The effect of simvastatin on OPN protein expression in immunodeficient mice was determined by immunofluorescence. OPN expression was decreased in the simvastatin-treatment groups (B) in comparison to the control group (A).
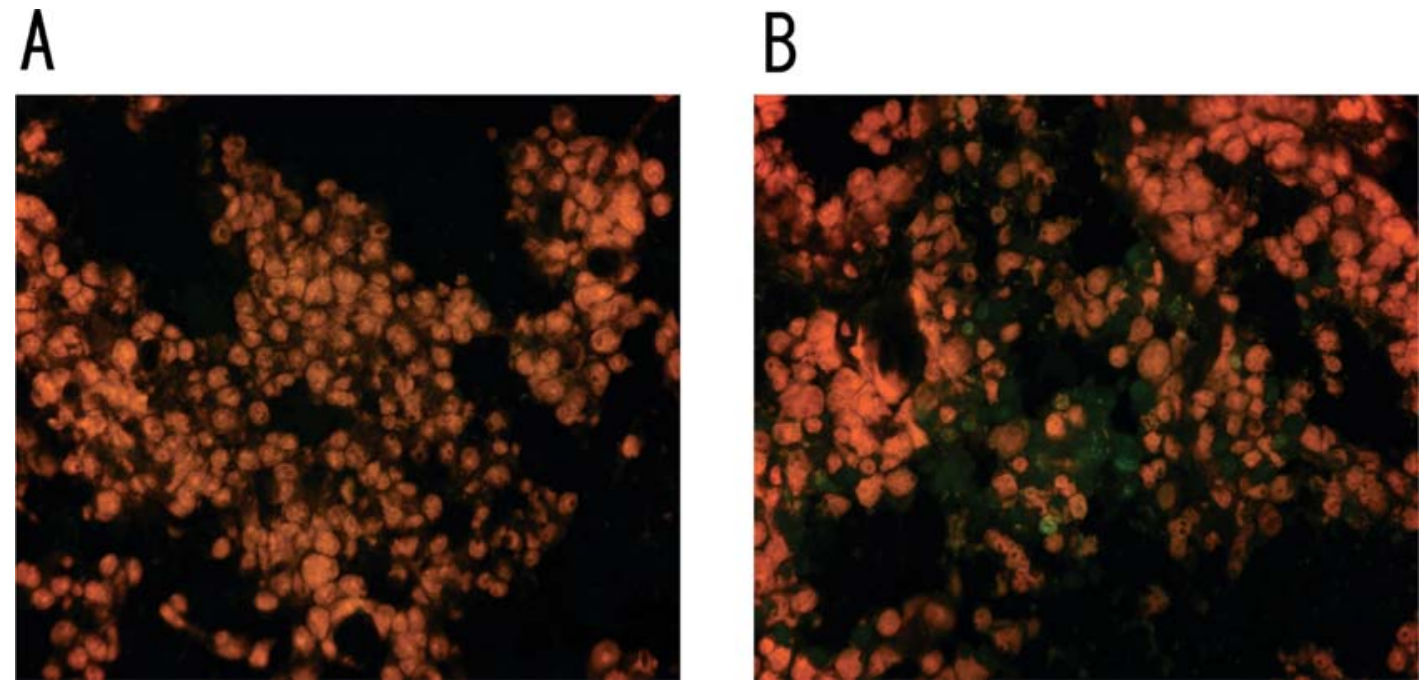

Figure 5. The detection of apoptosis by TUNEL assay. The green cells represent the apoptotic cells. Apoptosis was not detected in the control groups (A). However, apoptotic cells were detected in the simvastatin-treatment groups by the TUNEL assay (B).

simvastatin did not cause any side effects. None of the mice showed significant weight loss or any other serious side effects. Thus, $15-\mathrm{mg} / \mathrm{kg} /$ day simvastatin was considered to be safe.

\section{Discussion}

OPN is involved in cell invasion, adhesion, proliferation and apoptosis $(4,5,12,21,24,25)$. Our previous study demonstrated that OPN is highly expressed in ovarian cancer, especially in OCCC (12). We also reported that OCCC cells transfected with OPN-specific siRNA showed the reduction of cell invasiveness significantly. These data revealed that inhibition of OPN reduced cell invasiveness in vitro (12).

Human OPN promoters have a number of diverse homologous cis-acting consensus sequences (26). This suggests that OPN transcription may be sensitive to statins. Indeed, statins have been found to reduce OPN expression, although the precise underlying mechanism is unclear (19).
Statins are therapeutic drugs that effectively reduce plasma cholesterol levels and prevent coronary heart disease. Recent studies suggest that statins may be used for cancer treatment. Several statin antitumor effects have been observed: inhibition of cell proliferation, promotion of apoptosis, inhibition of angiogenesis, and prevention of metastasis (27-31). We hypothesized that the reduction of OPN expression may cause simvastatin-induced antitumor effects in ovarian clear cell carcinoma cells. Therefore, we first examined whether simvastatin treatment causes the reduction of OPN expression in OCCC cells in vitro and in vivo. Our data demonstrated that simvastatin inhibited OPN mRNA expression not only in vitro but also in the tumors of model mice. We think that simvastatin bound to the OPN promoter and reduced OPN mRNA expression. It is also reported that various statins deplete isoprenoids (32). Isoprenoids are important lipid moieties of $G$ proteins and $G$ protein subunits. Depletion of isoprenoids affects the expression of 
RMG-1

A

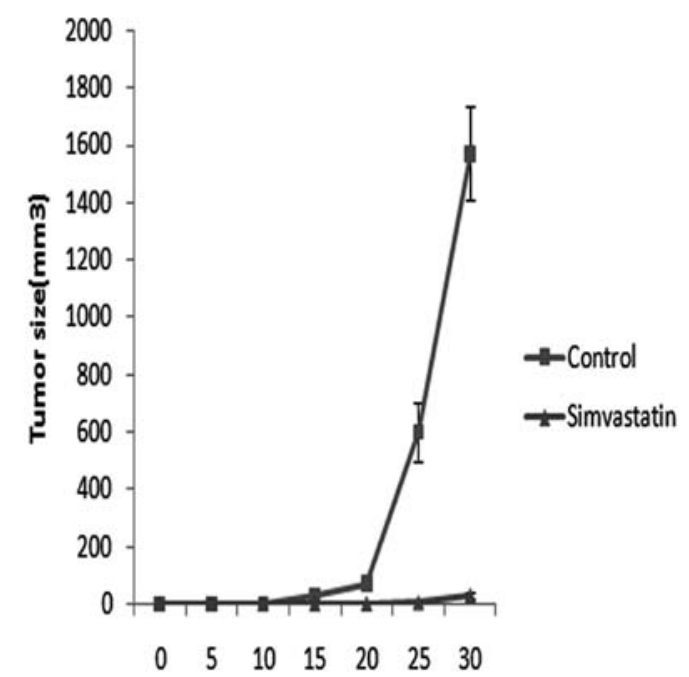

Days

B

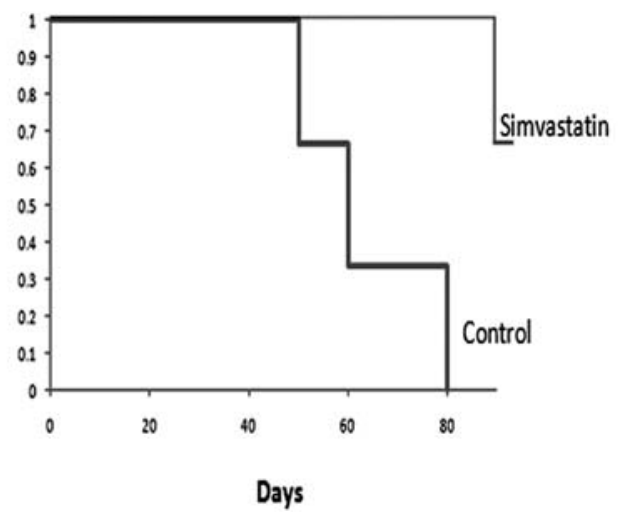

TOV-21G

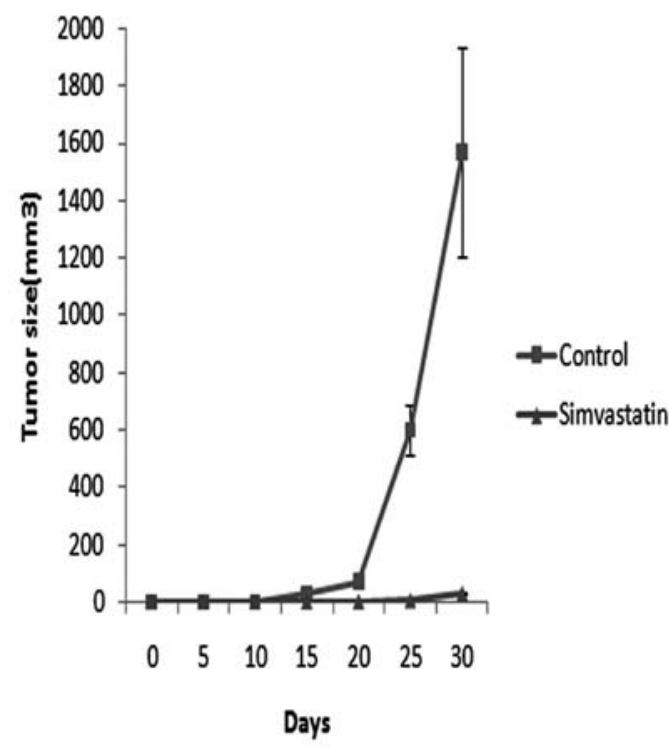

Survival rate

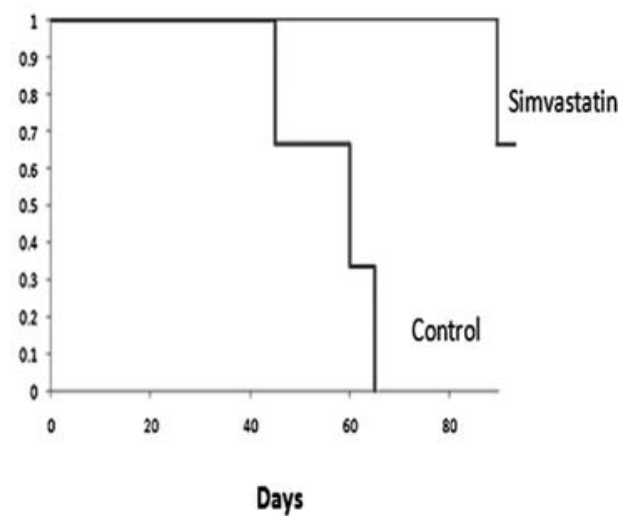

Figure 6. Antitumor effects of simvastatin in immunodeficient mice. (A) Tumor growth in the treatment groups was significantly inhibited in comparison with the control groups using both cell lines $(\mathrm{P}<0.05)$. (B) Mice treated with simvastatin survived significantly longer $(\mathrm{P}<0.05)$. At 90 days, the survival rate was $66.7 \%$ using both cell lines.

glycoproteins such as OPN. These data demonstrate the relationship between OPN expression and simvastatin treatment.

In general, various cancers are sensitive to statin treatment (33-35). Similarly, ovarian cancer cells may be sensitive to simvastatin treatment (12). Our data demonstrate that $10 \mu \mathrm{M}$ simvastatin significantly reduced the survival of the two cell lines to $62.5 \%$ (RMG-1) and $50.7 \%$ (TOV-21G). The mechanism of OPN-mediated cell proliferation has not been clearly elucidated $(4,36)$. Elgavish et al (37) reported that OPN treatment increased epithelial cell proliferation. Our previous study also suggested that OPN induced cell invasiveness in vitro by binding $\alpha \mathrm{v} \beta 1, \alpha \mathrm{v} \beta 3$, and $\alpha 5 \beta 1$ integrins in OCCC (12). These results revealed that OPN promoted the proliferation of ovarian epithelial cancers including OCCC.

Statins inhibit cancer cell proliferation in vitro and in vivo by the inhibition of HMG-CoA reductase and the depletion of isoprenoids (32). The HMG-CoA reductase inhibitordependent decrease in cell proliferation is due to the prevention of $\mathrm{G} 1$ to $\mathrm{S}$ phase transition in the cell cycle, down-regulation of cyclin-dependent kinases that facilitate cell cycle progression or up-regulation of cell cycle inhibitors (33). The highest concentration of simvastatin achieved in the plasma of patients receiving a 40-mg/day treatment was approximately $7.2 \mu \mathrm{M}$ (38). In addition, Spek et al (39) reported that the maximum tolerated dose of simvastatin was $15 \mathrm{mg} / \mathrm{kg} / \mathrm{day}$. Thus, much higher concentrations of simvastatin could be used. Our results demonstrated that one of the mechanisms of the anti-proliferative activity of simvastatin in OCCC cells was the down-regulation of OPN expression, in addition to HMG-CoA reductase inhibition and isoprenoid depletion.

Studies have demonstrated an association between OPN expression and the resistance to apoptosis, and that OPN inhibits apoptosis in a variety of cells (4). In addition, statins induce apoptosis through both the extrinsic and intrinsic 
pathways. Shibata et al (34) reported that lovastatin induced p53-independent mitochondrial-mediated apoptosis in a mouse mammary carcinoma. The sensitivity of different cell types to statin-induced apoptosis varies; acute myeloid leukemic and neuroblastoma cells are more sensitive than acute lymphoblastic leukemic cells (40). Apoptosis becomes evident following treatment with high concentrations of statins, and statin-induced cell inhibition is observed at lower concentrations. In this study, simvastatin exerted an apoptotic effect on OCCC cells, accompanied by growth inhibition. The simvastatin-mediated induction of apoptosis occurred concomitantly with a decrease in OPN expression and growth suppression. In accordance with previous studies, we treated with simvastatin at a dose of $15 \mathrm{mg} / \mathrm{kg} /$ day in the in vivo studies (39). Our in vivo study demonstrated that simvastatin inhibited the formation and growth of OCCC cells in immunodeficient mice. In addition, we determined that a high dose of simvastatin did not significantly induce weight loss or other serious side effects.

In this study, we examined the in vitro and in vivo effects of simvastatin on OCCC cell lines. Our data demonstrate that simvastatin reduced OPN expression and induced cell growth arrest and apoptosis. There seems to be considerable overlap of the various mechanisms by which statins exert their beneficial effects. Future studies are needed to reveal the detailed relationship between statins and OPN expression. In addition to the above-mentioned mechanisms, the antiinflammatory, immunomodulatory, and radiosensitizing properties of statins may contribute to cancer inhibition. Further confirmation of the anticancer effects of statins will increase the therapeutic scope for OCCC.

\section{References}

1. Giachelli CM and Steitz S: Osteopontin: a versatile regular of inflammation and biomineralization. Matrix Biol 19: 615-622, 2000.

2. Denhardt DT, Noda M, O'Regan AW, Pavlin D and Berman JS: Osteopontin as a means to cope with environmental insults: regulation of inflammation, tissue remodeling, and cell survival. J Clin Invest 107: 1055-1061, 2001.

3. Mazzali M, Kipari T, Ophascharoensuk V, Wesson JA, Johnson R and Hughes J: Osteopontin - a molecule for all seasons. QJM 95: 3-13, 2002.

4. El-Tanani MK, Campbell FC, Kurisetty V, Jin D, McCann M and Rudland PS: The regulation and role of Osteopontin in malignant transformation and cancer. Cytokine Growth Factor Rev 17: 463-474, 2006.

5. Chakraborty G, Jain S, Behera R, et al: The multifaceted roles of Osteopontin in cell signaling, tumor progression and angiogenesis. Curr Mol Med 6: 819-830, 2006.

6. Philip S, Bulbule A and Kundu GC: Osteopontin stimulates tumor growth and activation of promatrix metalloproteinase-2 through nuclear factor- $\mathrm{\kappa B}$-mediated induction of membrane type 1 matrix metalloproteinase in murine melanoma cells. $\mathrm{J}$ Biol Chem 276: 44926-44935, 2001.

7. Tammela J, Geisler JP, Eskew PN Jr and Geisler HE: Clear cell carcinoma of the ovary: poor prognosis compared to serous carcinoma. Eur J Gynaecol Oncol 19: 438-440, 1998.

8. Kim JH, Skates SJ, Uede T, et al: Osteopontin as a potential diagnostic biomarker for ovarian cancer. JAMA 13: 1671-1679, 2002.

9. Nakae M, Iwamoto I, Fujino T, et al: Preoperative plasma Osteopontin level as a biomarker complementary to carbohydrate antigen 125 in predicting ovarian cancer. J Obstet Gynaecol Res 32: 309-314, 2006.

10. Lu KH, Patterson AP, Wang L, et al: Selection of potential markers for epithelial ovarian cancer with gene expression arrays and recursive descent partition analysis. Clin Cancer Res 10: 3291-3300, 2004.
11. Kato N and Motoyama T: Overexpression of osteopontin in clear cell carcinoma of the ovary: close association with HNF-1 beta expression. Histopathology 52: 682-688, 2008.

12. Matsuura M, Suzuki T and Saito T: Osteopontin is a new target molecule for ovarian clear cell carcinoma therapy. Cancer Sci 101: 1828-1833, 2010.

13. Havel RJ and Rapaport E: Management of primary hyperlipidemia. N Eng J Med 332: 1301-1307, 1995.

14. Khaidakov M, Wang W, Khan JA, Kang BY, Hermonat PL and Mehta JL: Statins and angiogenesis: Is it about connections? Biochem Biophys Res Commun 387: 543-547, 2009.

15. Gauthaman K, Manasi N and Bongso A: Statins inhibit the growth of variant human embryonic stem cells and cancer cells in vitro but not normal human embryonic stem cells. Br J Pharmacol 157: 962-973, 2009.

16. Kwak B, Mulhaupt F, Myit S and Mach F: Statins as a newly recognized type of immunomodulator. Nat Med 6: 1399-1402, 2000 .

17. Wong WW, Dimitroulakos J, Minden MD and Penn LZ: HMGCoA reductase inhibitors and the malignant cell: The statin family of drugs as triggers of tumor-specific apoptosis. Leukemia 16: 508-519, 2002.

18. Minoretti P, Falcone C, Calcagnino M, et al: Prognostic significance of plasma osteopontin levels in patients with chronic stable angina. Eur Heart J 27: 802-807, 2006.

19. Takemoto M, Kitahara M, Yokote K, et al: NK-104, a 3-hydroxy3-methylglutaryl coenzyme A reductase inhibitor, reduces osteopontin expression by rat aortic smooth muscle cells. Br J Pharmacol 133: 83-88, 2001.

20. Heid CA, Stevens J, Livak KJ and Williams PM: Real-time quantitative PCR. Genome Res 6: 986-994, 1996.

21. Kon S, Maeda M, Segawa T, et al: Antibodies to different peptides in Osteopontin reveal complexities in the various secreted forms. J Cell Biochem 77: 487-498, 2000.

22. Johnson GA, Burghardt RC, Spencer TE, Newton GR, Ott TL and Bazer FW: Ovine Osteopontin: Osteopontin and alpha v beta 3 integrin expression in the uterus and conceptus during the periimplantation period. Biol Reprod 61: 892-899, 1999.

23. Kaplan EL and Meier P: Nonparametric estimation from incomplete observations. J Am Stat Assoc 53: 457-481, 1958.

24. Coppola D, Szabo M, Boulware D, et al: Correlation of Osteopontin protein expression and pathological stage across a wide variety of tumor histologies. Clin Cancer Res 10: 184-190, 2004.

25. Khan SA, Lopez-chua CA, Zhang J, Fisher LW, Sorensen ES and Denhardt DT: Solube osteopontin inhibits apoptosis of adherent endothelial cells deprived of growth factors. J Cell Biochem 85: 728-736, 2002.

26. Denhardt DT and Guo X: Osteopontin: a new protein with diverse functions. FASEB J 7: 1475-1482, 1993.

27. Hoque A, Chen $\mathrm{H}$ and Xu XC: Statin induces apoptosis and cell growth arrest in prostate cancer cells. Cancer Epidemiol Biomarkers Prev 17: 88-94, 2008.

28. Maksimova E, Yie T and Rom WN: In vitro mechanisms of lovastatin on lung cancer cell lines as a potential chemopreventive agent. Lung 186: 45-54, 2008.

29. Gbelcova H, Lenicek M, Zelenka J, et al: Differences in antitumor effects of various statins on human pancreatic cancer. Int J Cancer 122: 1214-1221, 2008.

30. Glynn SA, Sullivan DO, Eustace AJ, Clynes M and Donovan NO: The 3-hydroxy-3-methylglutaryl-coenzyme A reductase inhibitors, simvastatin, lovastatin and mevastatin inhibit proliferation and invasion of melanoma cells. BMC Cancer 8: 9, 2008.

31. Koyuturk M, Ersoz M and Altiok N: Simvastatin induces proliferation inhibition and apoptosis in C6 glioma cells via c-jun N-terminal kinase. Neurosci Lett 37: 212-217, 2004.

32. Jackobisiak M and Golab J: Potential antitumor effects of statins (Review). Int J Oncol 23: 1055-1069, 2003.

33. Lee J, Lee I, Park C and Kang WK: Lovastatin-induced Rho A modulation and its effect on senescence in prostate-cancer cells. Biochem Biophys Res Commun 339: 748-754, 2006.

34. Shibata MA, Kavanaugh C, Shibata E, et al: Comparative effects of lovastatin on mammary and prostate oncogenesis in transgenic mouse models. Carcinogenesis 24: 453-459, 2003.

35. Horiguchi A, Sumitomo M, Asakura J, Asano T and Hayakawa M: 3-hydroxy-3-methylglutaryl-coenzyme A reductase inhibitor, fluvastatin, as a novel agent for prophylaxis of renal cancer metastasis. Clin Cancer Res 10: 8648-8655, 2004.

36. Johnston NIF, Gunasekharan VK, Ravindranath A, O'Connel C, Johnston PG and EI-Tanani MK: Osteopontin as a target for cancer therapy. Front Biosci 13: 4361-4372, 2008. 
37. Elgavish A, Prince C, Chang PL, Lloyd K, Lindsey R and Reed R: Osteopontin stimulates a subpopulation of quiescent human prostate epithelial cells with high proliferative potential to divide in vitro. Prostate 35: 83-94, 1998.

38. Najib NM, Idkaidek N, Adel A, et al: Pharmacokinetics and bioequivalence evaluation of two simvastatin $40 \mathrm{mg}$ tablets (simvast and zocor) in healthy human volunteers. Biopharm Drug Dispos 24: 183-189, 2003.
39. Spek EVD, Bloem AC, Donk NWCJ, et al: Dose-finding study of high-dose simvastatin combined with standard chemotherapy in patients with relapsed or refractory myeloma or lymphoma. Haemtologica 91: 542-545, 2006.

40. Dimitroulakos J, Nohynek D, Backway KL, et al: Increased sensitivity of acute myeloid leukemias to Lovastatin induced apoptosis: A potential therapeutic approach. Blood 93: 1308-1318, 1999. 